\title{
Fiscalidad de esclavos en la Baja Edad Media
}

\author{
JOSÉ LUIS CORTÉS LÓPEZ
}

La esclavitud, sobre la que se pasa de puntillas cuando se trata de su implantación en España, se la suele considerar casi exclusivamente desde una perspectiva social, situando a los que la padecen en un estereotipado último lugar en la escala humana sin importancia ni protagonismo alguno. Cuando la visión se desliza rutinariamente hacia su vertiente económica, es casi seguro que se fijará la atención en la explotación de su fuerza laboral sin extenderse a otros aspectos que, en muchos casos, están por encima de esta consideración. La realidad española participa de este supuesto ya que nuestra esclavitud, en su casi totalidad doméstica y coyuntural, no fue mantenida como elemento necesario de producción acumulativa, sino por otros motivos circunstanciales y culturales que convierten al esclavo en un valor en sí, independientemente de su trabajo al que hay que dar sólo un carácter de complementariedad y no siempre. Con la documentación que tenemos a nuestro alcance, podemos señalar que en la Edad Media el esclavo en España es más importante por su aspecto fiscal que por cualquiera de las otras facetas que sobre él se pueden considerar desde el ámbito de la economía.

Los esclavos son parte importante, y, a veces, la principal, de los despojos que se consiguen en la confrontación bélica o en las incursiones y cabalgadas realizadas recíprocamente en suelo cristiano y musulmán o en Berbería, constituyéndose, por lo mismo, una parte esencial dentro de la economia de «botín", o "rapiña", tan importante en muchos momentos de la política económica medieval. El rey, al quedarse por ley y costumbre con el quinto ' de todo lo obtenido por este procedimiento, recibe una serie

Este derecho no sólo se extiende a la "ganancia que fiziessen quando el Rey venciese batalla, mas aun si lo ganassen em fazienda, o en lid o en cavalgada...". Partida II, Tit. 26. Ley V. 
de mercancías entre las que hay que contar las personas cautivadas que engrosarán su propia hacienda. Las cabalgadas que con relativa frecuencia se realizaron en Berbería supusieron, por este concepto, una buena entrada de dinero a las arcas reales, motivo por el cual eran bien vistas y, en muchas ocasiones, favorecidas ${ }^{2}$ por los monarcas que veian en ellas un buen modo de lucrarse sin exponer ni arriesgar para nada su propio dinero. Por eso, cuando se las suprime y se hace una encuesta posterior para ver si, realmente, "Su Alteza ha reydo deservida", todos los encuestados se expresan de forma coincidente:

"..trayan a ellas grandes presas de esclavos de que la renta e quinto de su Alteza hera cresçida..." ${ }^{3}$

$Y$ lo que en el siglo $x v$ había sido una constante en suelo africano prolongándose en el XVI, en tiempos anteriores se había practicado asiduamente en terreno peninsular con el ánimo de «acresçentar» el patrimonio no sólo del rey, sino de la nobleza e, incluso, de las personas particulares. Las Crónicas están repletas de hechos de esta índole que eran llevados a cabo por los reyes cristianos con intención de lucro:

«.. a nos es cierto por testimonios dignos de fe asin xristianos commo moros de los quales algunos dellos an memoria de nouanta annyos e más e andy de sixanta annyos e de mas que huyeron dezir a lurs padres e a lurs abuelos e a otras personas que en el tiempo que el Regno de Valencia era poblado de moros El Noble don berenguer detença en el tiempo trespasado defuncto con conpanya de hommes de cauallo e de pie e con las Uniuersidades de los lugares de clate et de darocha et de Theruel e algunos otros lugares del Regno de Aragon fazian entradas en el dicto Regno de Valencia e daqui trahian grandes caualgadas de bes tiares e de moros.." ".

La conquista de Sevilla por Fernando III le supuso también una gran riqueza en esclavos:

"Y tanta fue la muchedunbre de la captiuidad dellos, que si alguno quisiese comprar moro o mora, por diez marauedises de nuestra moneda tomaria qual quisiese; y, aun lo que es mas graue de creer, que leuando los

\footnotetext{
2 Los Reyes Católicos se expresaban asi por cédula dada en Salamanca el 2 de noviembre de 1502:

"por esta mi carta les fago çiertos e sanos los bienes e esclavos e otras qualesquier cosas que ovieren e tomaren de las dichas cavalgadas para agora e para siempre jamas como cosa avida y ganada en buena guerra...

AGS. Registro del Sello. Fol. 101.

3 La encuesta se realizó en Las Palmas el 16 de noviembre de 1505. AGS. Cámara de Castilla. Pueblos. Costa de Berbería.

4 Carta del Concejo de Chiva contestando a otra del Concejo de Daroca referente al milagro de los Santos Corporales. Jueves pridie nonas julii 1340. CAMPILLO, T. del, "Documentos históricos de Daroca y su comunidad". Zaragoza 1915.
} 
moros captiuos a la çibdad de Cordoua, dieron a la parte del rey en portaje tres mill captiuos: desto puede cada vno entender quan grand captiuerio de moros fue con el. Desde aquel dia, los moros no tornaron mas a pelear con los christianos..." ${ }^{5}$

El énfasis que se pone en relatar la cantidad de presas capturadas nos está indicando la importancia que ésta tenía para calibrar la magnitud de la gesta. Una victoria era tanto más celebrada cuanto mayores eran los despojos obtenidos; de aquí que, a veces, se precise minuciosamente el número de capturas en sus distintos apartados con la consiguiente sospecha en cuanto a la exactitud de las cifras o la evidente exageración de las mismas ${ }^{6}$. Más frecuentemente es emplear los adjetivos "mucho" y "grande" para magnificar una empresa y minimizar la imprecisión. Así, D. Lucas de Iranzo, tras una incursión a tierras de moros hace su entrada en Jaén.

"con muchos moros e moras cativos, atados en cuerdas e asaz ganados vacunos, cabrios e ovejunos, e grandes despojos, e muchas e grandes e ricas joyas e alfajas"?

Que estas incursiones fronterizas eran la ocasión para el mantenimiento de una corriente económica muy rentable para la hacienda real tanto por lo que directamente se entregaba al monarca en concepto del quinto como por otros impuestos indirectos que gravaban las transacciones de todo lo proveniente de estas confrontaciones que, en 1407, los arrendadores sevillanos de los derechos reales se quejaban de recaudar poco

"porque en el tiempo de la dicha renta era entonçes pas con los moros, de guisa que muy pocas veces se vendian en la çibdad moro ni mora..." ${ }^{8}$.

$Y$ lo mismo que se hacian operaciones violentas por tierra en busca de un botín que podía deparar artículos y productos diferentes, también éstas se realizaron por mar donde el objetivo fundamental era el cautivar hombres con vistas a un posible rescate. Esto no quita que, en ocasiones, la carga que llevaban los barcos era de gran valor para regocijo de los vencedores que, a los esclavos, unian también otras mercancías. Es lo que le aconteció a D. Pero Nino que, en camino hacia Sevilla para llevar al rey la parte que le correspondia de otras operaciones corsarias, tiene la

\footnotetext{
s LuCAS, Obispo de Tuy, "Crónica de Esparia”. Lib. IV. Cap. XCVIII. Versión de Julio Puyol. Madrid 1926.

- Así podemos constatarlo en la incursión hecha por ese «jefecillo" de Jerez de la Frontera que vuelve para su tierra con 23 moros, 3.000 vacas, 150 yeguas y 6.000 ovejas. "Cronica de Juan II», Cap. VIII. Año 1408.

"Hechos del Condestable don Miguel Lucas de Iranzo".

- Archivo municipal de Sevilla. Papeles de Mayordomazgo, 1407. N. 179.
} 
suerte de topar con una galeota que llevaba ricas mercancias apropiándoselas 10 mismo que los esclavos ${ }^{9}$. Lo que Pero Nuño encontró por sorpresa otros salian a buscarlo expresamente haciendo del corso y de la piratería un buen complemento de sus economías ${ }^{10}$. El esclavo que era reducido a tal condición por una acción violenta de este tipo y que por estar dirigida contra los «enemigos de la fe» era equiparada a «guerra justa", podia seguir tres caminos diferentes según la voluntad de quien lo habia capturado: quedarse a su servicio, ser vendido en pública subasta con los demás despojos o rescatarse por el «precio y cuantía» que se le asignara. La misma suerte podían correr los que, en concepto del quinto, llegaban a poder del rey.

La venta en almoneda está destinada lógicamente a conseguir el dinero suficiente para pagar a los que han intervenido en la contienda. Ordinariamente sólo se vendía por este método una parte de los esclavos capturados, pero también, a veces, asistimos a la venta de todos ellos, como parece desprenderse de la narración sobre la toma de Mallorca:

"Hácese la división del despojo conforme lo concertado; y quién la hace. Grande fue la riqueza y el despojo que los cistianos hallaron en la ciudad; y luego se entendió en hacer almoneda de la ropa y esclavos para hacer repartición conforme a lo que el rey tenla acordado." "

En estos casos el «rescate» quedaba supeditado a la voluntad del comprador quien, en no pocas ocasiones, podía sacar del mismo más dinero que lo que el esclavo le hubiera costado en la subasta o en la venta

\footnotetext{
9 ¿Estando allí (Cartagena) llegó la carta del rey, que se biniese con sus galeras para Sevilla, e dexase las galeras, e se fuese luego para él. Entonzes mandó el capitán meter en las naos todos los moros e las otras cosas que perteneçian al rey, que las llevasen a la tarazana de Sevilla. E partieron las galeras, façiendo la via, e alcanzaron una galeota de Aragón que benia fretada de mercaderes de Berbería e falló en ella moros e moras negras, e otros esclauos; e toda cargada de çera, e grana, e alquizeres, e mercadurias de grand valia. E tomó toda la mercaderia e los esclauos, e mandó soltar la galeota, segund que era derecho...".

Gutierre Diez de Gamez, Alférez, "El Victorial: Crónica de Don Pero Niño, conde de Buelna». Cap. L. Versión de J. Mata Carriazo. Madrid 1940.

10 Aunque el siguiente acontecimiento tiene lugar a mitad del xvı, no es sino un hecho más de una tradición existente que, sobre todo, se desarrolló en el Mediterráneo:

“Moffen Vincente Peñarroja... en el año mil quinientos quarêta y siete, armó a fu cofta el Grao de Valencia dos galeotas para yr en coffo y como tuuieffe que otras dos de Turcos corrian nueftro mar, con grande adaño de los nauegantes, falió en butca dellas, las halió delante de Calpe: y hauiéndolas enveftido, las entró por fuerça, con fer de muchos mas bancos que las fuyas. Captiuó defta vez ciento y fetenta Turcos, y dio libertad a ciêto y treynta efclauos Christianos: y con toda la preffa, dio la buelta para Valencia, donde fue recebido con mucho regozijo de la ciudad, y le quedio para siempre el renôbre de Peñarroja de las galeotas". Escolano, G., "Década Primera de la Historia de Valencia". Valencia, 1610. Lib. VIII. Cap. XXX. Núm. 5.

$"$ Zufita, J., "Anales de Aragón”. Lib. III. Cap. XIV. 31 de diciembre de 1230.
} 
inmediata que se hacía después de la batalla. Cuando terminada la conquista de Baleares el rey se dirige a tomar el reino de Valencia, tras la toma de la torre de Moncada nos dice la Crónica:

"Los captiuos fuerô mil cieto quarêta y fiete: â cuyo refcate, y del precio de los defpojos fe facarô cien mil befantes: ê valia cada befâte nueue faueldos Barcelonefes. El rey folamête tomo para fi ci^æ cautiuos, ê eran de la mefma Ciudad de Valencia: y lo demas repartio con fus Ricos hombre y caualleros..." ${ }^{12}$

En estas circunstancias el precio de cada cautivo fue solamente de 87 , 18 besantes cada uno, y aún podemos pensar que fue menos, pues en esta cantidad hay que incluir también el precio de otros despojos. Sin embargo, el propio rey, acuciado por las necesidades económicas para pagar a sus acreedores, se ve obligado a vender estos cien moros que le habían correspondido tras la caída de Muceros.

"Con esta victoria y con muy gran priesa se volvió el rey por Torres-torres; $y$ antes que llegase a Albentosa por gran necesidad y falta que tenía de dinero rescataron cien moros que llevaban por diez y siete mil besantes. $Y$ vínose a Zaragoza y pasó a Huesca", ${ }^{13}$.

Es decir, que cada esclavo le valió un importe medio de 170 besantes, lo que le supuso un aumento del 95 por $100{ }^{14}$ respecto al valor obtenido en el reparto.

El rescate, pues, es una receta fiscal excelente para allegar fondos a la corona y, aunque el montante del mismo es circunstancial dependiendo de los condicionamientos concretos, no obstante hubo momentos en los que se oficializó el precio, constituyendo esta normativa la mejor prueba de la importancia económica que el rey dio a esta forma de captación de ingresos. Es lo que ocurrió con el pago del rescate que los moros cautivos granadinos debieron dar para obtener su condición de libres:

«b) Los preçios que deven apreçiar los moros de Granada que fueron e estan cativos son estos:

Los moros de quinze años hasta veynte a honze mill mrs.

Los de veynte años hasta treynta a diez mill mrs.

Los de doze años hasta catorce, trezientos reales cada uno.

Los moros de diez años hasta honce, syete mill e quinientos mrs. cada uno.

Escolano, O.c. Lib. VII. Cap. IV. Núm. 10.

ZURITA, O.c. Lib. III. Cap. XXI.

it Escolano nos narra asi este acontecimiento:

«... el Rey fe contento por refcate de fus ciê Moros con ocho mil libras, con que hizo pago a 108 Mercaderes que le trahian acoffado por emprenitos de dinero: y con efto fe partio de Muceros a bufcar mas, para la continuacion de la guerra de Valencia...". O.c. Lib. III. Cap. IV. Núm. 11 
Los de seys hasta nueve, çinco mill mrs. cada uno.

Los moros de treynta y uno años hasta quarenta, ocho mill mrs. cada uno.

El moro de quarenta e un años hasta çinquenta, seys mill dozientos mrs. cada uno.

Los moros desde çinquenta hasta sesenta anos, çinco mill mrs. cada uno.

El moro de sesenta años arriba e de tres abaxo, tres mill mrs. cada uno.

Las moras de quinze años hasta veynte e çinco, quince mill e quinientos mrs. cada una.

Las moras de veynte e çinco años hasta treynta, doze mill mrs. cada una.

Las moras de doze años hasta catorze, doze mill e quatroçientos mrs. cada una.

La mora de diez años hasta honze, nueve mill e trezientos mrs.

La mora desde treynta e uno hasta quarenta años, nueve mill e tre zientos mrs.

La mora desde quarenta e uno hasta çinquenta años, syete mill mrs.

La mora desde çinquenta años hasta sesenta, çinco mill e quinientos mrs.

La mora de sesenta años arriba e de tres abaxo, tres mill mrs. cada una.

Los dichos preçios de los dichos moros e moras se han de hazer seyendo sanos e bien dispuestos de sus personas, e, sy tales no son, no los valen, asy que aveis de mirar que segund fuere cada uno asy lo aveis de apreçiar» 15.

Contrastando y ordenando estas cantidades tenemos el siguiente cuadro comparativo:

\begin{tabular}{ccc}
\hline Edad & Hombres & Mujeres \\
\hline $0-3$ & $3.000 \mathrm{mrs}$. & $3.000 \mathrm{mrs}$. \\
$6-9$ & $5.000 \mathrm{mrs}$. & $6.200 \mathrm{mrs}$. \\
$10-11$ & $7.500 \mathrm{mrs}$. & $9.300 \mathrm{mrs}$. \\
$12-14$ & $10.200 \mathrm{mrs}$. & $12.400 \mathrm{mrs}$. \\
$15-20$ & $11.000 \mathrm{mrs}$. & - \\
$20-30$ & $10.000 \mathrm{mrs}$. & - \\
$15-25$ & - & $15.500 \mathrm{mrs}$. \\
$25-30$ & - & $12.000 \mathrm{mrs}$. \\
$31-40$ & $8.000 \mathrm{mrs}$. & $9.300 \mathrm{mrs}$. \\
$40-50$ & $6.200 \mathrm{mrs}$. & $7.000 \mathrm{mrs}$. \\
$50-60$ & $5.000 \mathrm{mrs}$. & $5.500 \mathrm{mrs}$. \\
60 y más & $3.000 \mathrm{mrs}$. & $3.000 \mathrm{mrs}$. \\
\hline Precio medio & $6.890 \mathrm{mrs}$. & $8.320 \mathrm{mrs}$. \\
\hline
\end{tabular}

15 AGS. Mercedes y Privilegios. Leg. 20. Fol. 56. 
Como se vé, las mujeres superaron en valor a los hombres en cantidades acordes con la edad y, aunque se pueden aducir razones de índole convencional como su posible maternidad, carácter más sumiso, menos disposición a la fuga, mayor longevidad, etc., para explicar este fenómeno, el hecho fundamental que sustenta esta discriminación valorativa es que la esclavitud en España, tanto en la baja Edad Media como en la época moderna, tiene una dimensión prioritariamente doméstica donde a la mujer se le ofrece un campo de acción más extenso que al hombre. Por otra parte, y esto es importante resaltarlo, los precios no están impuestos de forma caprichosa, sino después de un detenido estudio que recoge, lógicamente, la fluctuación de los precios esclavistas y se ajustan perfectamente a la demanda del mercado. La prueba irrefutable de esto es la consonancia del pago medio del rescate de estos moros granadinos con el precio, también medio, del esclavo para el período 1453-1500 que, según nuestros estudios, fue de $6.774 \mathrm{mrs}$. para los hombres y $8.001 \mathrm{mrs}$. para las mujeres ${ }^{16}$. La pequeña diferencia existentes entre el rescate de los cautivos granadinos y el precio de venta del esclavo en la segunda mitad del xv está en que, en este último caso, la media incluye también los precios de esclavos negros y loros que, al ser más baratos, originan este pequeño desnivel.

Los rescates que, ordinariamente, se hacian con dinero, podian también llevarse a cabo en especie o bien mezclando ambos elementos. Sin embargo, las personas principales solían rescatarse entregando un cierto número de esclavos según la calidad del personaje:

«Da sesenta moros el rey a Guillén Zagardia para rescate de su sobrino. De los cuales hizo merced a Guillén Zagardia para rescatar en cambio de ellos a Guillén de Aguilón su sobrino que estaba cativo en Valencia, y salió entonces de su poder por estos sesenta moros que se dieron por solo su rescate" ${ }^{17}$.

Este método, tal vez menos costoso para el rescatado, era muy beneficioso para el perceptor quien, vendiendo todos los esclavos que había recibido, obtenía más dinero que el que se hubiera exigido directamente en

15 Los precios medios obtenidos según la edad de los esclavos en el período 1453-1500 son:

\begin{tabular}{crrrrrrrr}
\hline Edad & $10-13$ & $14-16$ & $18-21$ & $22-25$ & $28-30$ & $35-45$ & 60 & Total \\
\hline Mujeres & 10.500 & 11.600 & 8.350 & 9.584 & 7.800 & 6.172 & 2.000 & 8.001 \\
Hombres & 7.750 & 8.750 & 9.025 & 7.867 & 5.250 & 3.773 & 5.000 & 6.774 \\
\hline
\end{tabular}

CORTÉs López, J. L., "LoS origenes de la esclavitud negra en España”. Salamanca-Madrid 1986, pág. 107.

17 ZuRITA, O.c. Lib. III. Cap. XXI.

Era esta una costumbre que se practicó incluso fuera de nuestras fronteras cuando se iba a las costas de Berberia a "saltear" y adquirir cautivos con vistas al beneficio económico del rescate: 
el rescate. El pago en dinero o especie se ve bien reflejado en las Capitulaciones con motivo de la toma de Málaga:

"Primeramente que todos los dichos moros e moras, asy viejos como moços, asy pequenos como grandes o de teta e los esclavos moros que ellos tenian por servidores, se ayan de rescatar e rescaten e nos ayan de dar a pagar e den e paguen por cada cabeça de cada uno de todos ellos, porque sean libres, e por todos sus bienes muebles, treynta doblas de oro de veynte e dos quilates de peso, de haçenes, o el presçio que entre ellos vale pagado en oro e plata e perslas e ljofar e seda e joyas de seda que sean de dar e tomar, razonando cada cosa en el presçio que justamente se estimare e valiere" ${ }^{18}$.

Este texto, además de revelarnos una determinada forma de pago, es también muy importante por el precio unitario de rescate en torno a los $11.000 \mathrm{mrs}$., sin tener en cuenta las características peculiares de cada rescatado y, como se ve, está por encima de la media de lo exigido en Granada cinco años más tarde.

Un caso especial lo constituyen los judios malagueños para quienes se suscribe un rescate colectivo, hecho bastante insólito, y cuya forma de proceder no hemos encontrado en otros lugares ni para otros grupos. Bien es verdad que también se los había tratado como grupo al exigirseles una contribución de 16.000 castellanos de oro para la guerra de Granada en la reunión que las aljamas habían tenido en Maqueda, de forma que los que se apartaran de la misma "tomen por cabtyvos todas e qualesquier personas que los fallaren e los aherrojar e se aprovechar e servir dellos sin pena ni calunia alguna..." ${ }^{19}$. Pues bien, los judíos malagueños debian pagar 10 millones de mrs. por su liberación, cantidad que se reuniria merced a la solidaridad de las aljamas repartidas por los reinos de Castilla y Aragón. A tal fin se otorgó un seguro para 20 judíos y ayudantes con objeto de visitar estas comunidades y recaudar todo lo

«...E tendo assim encaminhado, goube parte como um mercader de Castela que se chamava Marcos Cisfontes, tinha daquele lugar XXVI Mouros já regatados para se darem por certos Guineus. E por que seu navio podesse ter alguna causa em sua ida, fez saber ao dito mercader que se the prouvesse que Ihe seriam levados seus Mouros aquele lugar, naquela caravela que assim tinha encaminhada, com tanto que lhe desse certa parte do que lhe sobreviesse do resgate... E tomando sua seguranza, foi entre eles, onde trautou por tal guisa que vez trazer a caravela cincoenta e um Guineus, pelos quaes foram dados XVIII Mouros..."

ZuRARA, G. E., "Cronica dos feitos natáveis que se passnram na conquista de Guiné por mandado do infante D. Henrique". Cap. XChIl. Año 1447.

18 AGS. Patronato Real. Leg. 11. Fol. 5. Málaga 4 de septiembre de 1487.

19 Carta a Abrahán Seneor para que recoja esta contribución. Sevilla 30 de noviembre 1484 AGS. Registro del sello. Fol. 83. 
necesario ${ }^{20}$. Este dinero se consigue y las arcas reales ingresan estos 10 millones de mrs. tras lo cual los judíos no sólo consiguen su libertad, sino que, incluso, pueden marchar a vivir a cualquier lugar de Castilla:

«...Sepades que los judios e judias que fueron catyvos en la çibdad de Malaga quando el rey mi señor la gano de poder de los moros ene migos de nuestra santa fe catholica, ygualaron el rescate de sus pesonas e bienes por dies cuentos de maravedis... e por lo restante a conplimiento de los dichos dies cuentos de maravedis... se obligho Rabi Mayr... para lo pagar... E agora el dicho ¡Rabi Mayr nos suplico e pidio por merçed que pues avia fecho la dicha obligaçion en la forma ocntenida en el dicho asiento le mandasemos dar carta de ahorria para los dichos judios e judias segund que es e fue asentado e yo tovelo por bien... " ${ }^{21}$.

Pero la rentabilidad de los esclavos obtenidos como botín de guerra, no sólo se ceñía a lo que el rey percibía en concepto del quinto, sino que, a veces, también le servía para atender a otras recesidades de tipo económico o social. A este respecto nada hay más ilustrativo que la distribución que se hace con los cautivos malagueños y el destino que se les da para cubrir diversos frentes:

"Lunes veinte y seis dias del mes de Agosto, los reyes Católicos con acuerdo del cardenal de España, hicieron un repartimiento en tres partes de los moros que se tomaron en la ciudad de Málaga, que no fuesen inútiles. $Y$ la primera parte ofrecieron por amor de Dios para redención de los cautibos cristianos que estaban en la parte de África...; otra segunda parte mandaron repartir a todos los cavalleros y a sus consejeros y a todos los capitanes y a otros hijos de algo y oficiales y a otros soldados castellanos, aragoneses, valencianos, portugueses y a otras naciones que sirvieron en esta guerra, dándole a cada uno respecto de su calidad y servicios; la otra tercia parte tomaron los reyes para ayuda de los grandes gastos de la guerra y desta su parte repartieron cien moros de los gomeros para el Papa y a la reina de Nápoles cinquenta moras doncellas y a la de Portugal treinta moras doncellas y demás a más repartió la reina mas de otras doscientas moras a muchos señores del reino y a los dueños y doncellas de palacio" ${ }^{22}$.

20 «...tomamos e reçebimos so nuestra guarda a enparo e defendimiento realk a veynte udios de los que fueron vecinos de la dicha çibdad de Malaga, los quales ilevan cartas de don Abrahen Seneaor, juez mayor de las aljamas destos nuestros regnos que digan como son aque llos de los dichos veynte judios de Malaga para que puedan andar e anden libre e seguramente pidiendo las dichas limosnas en las dichas aljamas de los dichos nuestros reynos de Castilla e de Aragón... mandamos que con los dichos veynte judiog puedan andar otros qualesquier judios destos nuestros regnos e señorios e gozen deste dicho nuestro seguro asy como los dichos veynte judios..."

AGS. Registro del Sello. Fol. 84. Valladolid 9 enero de 1489.

21 Ibidem. Fol. 1. Jaén 6 de junio 1489.

22 JoRquera, Henriquez de, "Anales de la ciudad de Granada" (1482-1645). Lib. Il. Ano 1487.

Destinar moros cautivos para redimir cristianos es un hecho que de vez en cuando encon tramos en la documentación ernanada de la corona. Por una carta firmada en Toledo el 28 de marzo de 1480 se insta al corregidor de Murcia para que acabe el pleito entre Diego de Alcalá y Diego de 
El esclavo-regalo, que cumple conjuntamente funciones económico sociales, aparece bastante en la documentación acompañando a cantidades de dinero, animales y otros bienes mobiliarios. Alfonso el Casto, que manda a Fruela y Basuilico como embajadores a Carlomagno.

"le envió muy ricos dones y presentes de armas, caballos y esclavos, y un pabellón de extraña labor y grandeza" ${ }^{23}$.

Fernando del Pulgar recoge, así, el destino de los moros malagueños entregados como regalo inspirándose en la misma fuente que los Anales de Jorquera:

«E primeramente enbiaron al Papa çient moros de aquellos moros gomeros, e enbiaron a la reyna de Napoles çinquenta moças donzelias, e enbiaron a la reyna de Portogal otras treynta donzellas. E la Reyna fizo merçed e repartio otra grand cantidat de moras por algunas dueñas de su reyno, e por otras que continuauan en su palaçio..." ${ }^{24}$

La economia de botín representó, pues, para la hacienda real unos ingresos fiscales extraordinarios que, en su vertiente esclavista, estaban concretados en el pago de un rescate, en la entrega del quinto de cuantos esclavos se capturasen y en la percepción, de nuevo, de este impuesto en cuantas transacciones se hicieran con los cautivos no pertenecientes a la corona. Tan importante fue este último aspecto, que los ingresos percibidos por esa vía superaron a los provenientes por otros conceptos considerados de primera magnitud. En Valencia, por ejemplo, tenemos que, al

Monzón, sobre unos moros entregados a éste para rescatar ciertos cautivos en Granada y que seguían aún sin ser liberados: AGS. Registro del Sello. Fol. 175.

El intercambio de cautivos es algo que recoge asi el fuero de Daroca:

"Si quis vicinus daroce fuerit captivus in terra paganorum et alius uicinus tenuerit alium captivum sarracenum in daroca pro quo christianus possit exire parentes captiui reddant domino sarra ceni tantum pro quanto traxit illum de almoneda et suum panem et XII d. pro carceratge et dent illum pro captiuo christiano. Si autem captiuus christianus pro illo exire nequiuerit diominus eius recuperet eum si uoluerit reddito pretion.

Archivo Municipal de Daroca. Doc. núm. 1.

${ }^{23}$ ZURITA, O.C. Lib. 1. Cap. III. Hacia el 798. Excelentes ejemplos de exclavos comprados por el rey para luego entregarlos como regalo los tenemos en las Cuentas del Tesorero Gonzalo de Baeza: AGS. Contaduria Mayor. Leg. 6: «libro de la quenta del carto y datta del thesorero Gonçalo de Baeça" (1477- 1491) y Leg. 15 (1492-1 504):

1483: “Al thegorero de Vizcaya $7000 \mathrm{mrs}$ por un esclauo que mando su Alteza para dar al liçenciado de Luçena..."

1485: "Costaron tres esclauas, que su Alteza mando comprar, las dos para enbiar al iley, nuestro Señor, a Valençia, e la una para Juan de Aluarnaez, 30.000 mrs."

1487: "Que se dio para çinco esclauas que enbio la ynfante a doña isabel de Sosa a Portogal lo siguiente..."

1489: "... dio e pago a Maria de Robles para conprar vn esclauo cristiano..."

${ }^{24}$ "Crónica de los Reyes Catóficos". Versión J. Mata Carriazo. Cap. CCXXIII. 
final del siglo $x \mathrm{v}$, el quinto de las transacciones esclavistas tenía un valor superior al "almudín» y al «tercio del pan y vino»:

\begin{tabular}{cccc}
\hline Años & Almudín & $\begin{array}{c}\text { Tercio del pan } \\
\text { y vino }\end{array}$ & Esclavos \\
\hline 1491 & $5218 \mathrm{~s} .2 \mathrm{~d}$. & $8.000 \mathrm{~s}$. & $10.052 \mathrm{~s} .2 \mathrm{~d}$. \\
1496 & $3861 \mathrm{~s} .6 \mathrm{~d}$ & $6.237 \mathrm{~s}$. & $8.461 \mathrm{~s} .6 \mathrm{~d}$. \\
\hline
\end{tabular}

Para la Corona de Castilla los ingresos percibidos por el concepto del quinto tienden a organizarse en cuentas homogéneas bien entrado el siglo XVI. En la época que estamos considerando el archivo de Simancas, tanto en sus secciones "Consejo de Junta de Hacienda" (1369-1574) y "Contaduría Mayor", en su primera época como en "Guerra Antigua", "Cámara de Castilla" y otras de menor importancia, sólo nos ofrecen retazos aislados que nos dejan entrever la importancia económica de este derecho. Por ejemplo, de las cuentas de Alonso Fajardo, gobernador de Las Palmas a finales del XV, escogemos estos apuntes proporcionados por él mismo y por su mujer resaltando el hecho de la propiedad del medio quinto concedida por el rey. En ocasiones éste renunciaba a parte de este impuesto a su totalidad en favor de quien lo considerase oportuno bien para favorecer ciertas empresas o bien para remunerar servicios:

«... e mas resçibio el dicho senor governador mill e seysçientos e veynte e syete maravedis de çierto quinto de çiertos esclavos que traxo a esta ysla Gonçalo Cordonero.....

"Del quinto de çiertos esclavos... XIX.U.CCXXVII mrs."

«Paresçe por la cuenta que da el susodicho que reçibo la dicha dona Elvira de la mitad de çierto quinto, quatro pieças d'esclavos berberiscos, un moço apresçiado en MX.U. mrs. e un viejo apresçiado en IX.U. mrs. e un viejo apresçiado en IX.U. mrs. e una mochacha en IIII.U. mrs. e una esclava vieja muncho vieja en IIII.U.D. mrs. de lo quales se han de sacar X.U. mrs. del esclavo moço porque lo tomaron los protogueses e lo lle varon asy que queda al cargo XVII.U.D. mrs.» ${ }^{26}$.

En la encuesta aludida al principio de este trabajo, uno de los testigos mencionó una de las cabalgadas del también gobernador canario Pedro de Vera,

26 AGS. Contaduría Mayor. Primera época. Las Palmas 17 de enero de 1947. Alcalá de Henares 27 de marzo 1498 y 5 de marzo 1498.

Por cédula dada en Valladolid el 13 de julio de 1492 los Reyes Católicos entregaron la mitad del quinto al capitán Alonso de Lugo de las presas que hiciera en Berbería. AGS. Registro del Sello. 
"porque tenía merced del dicho medio quinto de Sus Altezas, e que en un ano ovo del dicho medio quinto mas de trescientas mill mrs. e esta ysla estava muy poblada e rica e muchos mercaderes e las rentas de Sus Altezas muy mas acreçentadas e Dios Nuestro Señor acreçentava los bye nes temporales en esta ysla por la dicha guerra que contra los ynfieles se hazia los cuales despues que çeso esta ysla e los vesinos de ella han venydo e estan en mucha neçesydad..."

La cita es bastante ilustrativa para dejar constancia de la amplitud de las cabalgadas así como de su gran rentabilidad; los $300.000 \mathrm{mrs}$. que se lleva Pero de Vera en virtud del medio quinto suponen unas transacciones por valor de 3.000 .000 de mrs. para las cabalgadas de un solo año.

\section{FISCALIDAD ORDINARIA}

Entendemos por este concepto los ingresos proporcionados por todo lo relacionado con el mundo de los esclavos pero que están bajo control de la autoridad y, por lo tanto, sometidos a una legislación consagrada por la fuerza de la costumbre. Nos referimos a la alcabala, almojarifazgo, portazgo, aduanas, peages, sanciones, etc. cuyo control directo a veces se ejerce por la Hacienda real y, en otras ocasiones, por la autoridad municipal según el ámbito y la naturaleza del impuesto. El quinto, que, por una parte, lo hemos situado dentro de la fiscalidad extraordinaria relacionada con la economía de botín por la incertidumbre del resultado, también lo podemos catalogar como una receta ordinaria no sólo porque la práctica de «saltear» era algo concebido con vistas al acaparamiento de bienes de la que el rey se llevaba la quinta parte, sino también porque esta proporción se había de entregar a la Hacienda en todo intercambio esclavista realizado en cualquier parte y fuera de los escenarios bélicos ${ }^{27}$. Raramente asistimos a una modificación de este derecho aunque alguna vez nos podemos encontrar con una variante del mismo; tal es el caso de un tal Lope de Cantos, vecino de Jaén, a quien los reyes le dan una carta de merced para que sólo entregue la sexta parte de lo que le correspondió de la venta de un esclavo moro ${ }^{28}$.

27 Era frecuente el intento de sustraer este derecho a la Hacienda real o cobrar indebidamente, por lo que es abundante la intervención del monarca exigiendo su correcta aplicación. Por ejemplo, en carta dirigida a Alonso de Almagro, alcaide de la fortaleza de Moguer y a otros dos vecinos de la villa de Palos, se les pide la entrega a un escribano de cámara del "quinto de çiertos esclavos" que habian tomado indebidamente y que pertenecian al rey: A.G.S. Registro del Sello. Fols. 231-233. Jerez de la Frontera 2 de noviembre de 1477.

28 Ibidem. Fol. 354. Jaén 14 de julio 1489. 
La alcabala, según expresión de D. Ramón Carande, "refunde, junto a gravámenes sobre las operaciones de mayoristas, otras existentes sobre transmisión de heredades, sobre las ventas de artículos de comer, beber y arder y sobre múltiples manufacturas" ${ }^{29}$. Aunque en esta descripción parece no haber lugar para el comercio de esclavos nada más que en el primer caso, sin embargo se aplicó este impuesto a la compraventa esclavista apareciendo su pago asociado a otros artículos. En Granada la alcabala que se ha de pagar por el esclavo se equipara a la del pan, leña, carbón y otros; en Guadix a la de la ropa, pescado, aceite, herraje...; en Sevilla a la de las aves, caza, zapatos... En una relación de ingresos y gastos de la administración de la Frontera desde el 1 de noviembre de 1331 hasta la misma fecha del año siguiente, vemos que, para el Arzo bispado de Sevilla, entre otros ingresos se constata:

o... el alcauala de los catiuos con fu alenzel, III J mill LXXVIIJ mr. II ff." ${ }^{30}$

En una concesión especial del rey al portugués Gonzalo de Paria, manda a las autoridades pertinentes que no le clieven alcabalas de sus esclavos» que venda en Castilla en reparación por otros que injustamente le habian sustraído ${ }^{3 !}$.

Este impuesto apenas queda reflejado en las cartas de compraventa que se hace entre particulares y en los pocos casos que hemos dado con alguna precisión al respecto pertenecen al siglo xVI. En Sevilla, en 1505, el acta notarial de la venta de una esclava señala expresamente "que no paga alcabala" "32. En Salamanca, cuyo archivo de Protocolos estamos especialmente estudiando en su vertiente esclavista, raros son los casos en que se precisa el pago de este impuesto; pero algunos documentos se expresan así al respecto una vez que se indica el precio de la venta:

“.. horra de alcavala que haveys de pagar vos...»

«... horro de alcavala...»

“... y queda a vuestro cargo de pagar el alcabala..." ${ }^{33}$.

En otro caso se dice el precio añadiendo a continuación «menos quatro rreales" ${ }^{34}$ no sabiendo si esta precisión se refiere al pago de la alcabala 0 de otro impuesto o es, simplemente, el precio ajustado. El ignorar el por-

"Carlos Quinto y sus banqueros". Lib. II. Cap. VI.

Archivo Histórico de la Catedral de Toledo. Caja 231.

AGS. Registro del Sello. Fol. 72. Vitoria 24 de diciembre de 1483.

ARChIVo de protocolos notariales de SeVILla. Of. 5. Leg. 1.

33 AfChivo de protocolos notariales de SalamanCA. Leg. 3148. Fol. 282 (1543); Leg. 3364

Fol. 288 (1543); Leg. 3369. Fol. 296 (1550) Leg. 3372. Fol. 691 (1553)

34 Ibidem Leg. 3146. Fol. 150 (1541). 
centaje exacto de la alcabala (algunos autores hablan de un 10 por 100 , porcentaje más teórico que real) no nos permite aventurar una solución a este caso.

El almojarifazgo, tomando otra vez las directrices del desaparecido profesor Carande ${ }^{35}$, tiene una estrecha relación con el tráfico esclavista y gravaba las mercancías que entraban en una ciudad. El esclavo, pues, caída dentro de su ámbito, pero tampoco podemos señalar un porcentaje exigido, pues en la documentación, como sucedía con la alcabala, tampoco aparece asiduamente en las cartas de compra-venta. Casos como el de un mulato de 18 por el que se pagan 100 ducados más "el alcabala y almoxarifazgo que montaron 52 reales" ${ }^{36}$, son raros de descubrir y, aún así, al designar una cantidad para dos destinos diferentes sigue resultando difícil delimitar la cuantía de cada uno. Que este impuesto gravaba también a los esclavos se deduce claramente de una carta real reclamando este derecho a un mercader florentino que había traído a España negros procedentes de Guinea y que habian pasado sin ni siquiera pagar los aranceles de la aduana ${ }^{37}$. En el siglo XVI, con un perfeccionamiento de la administración y un mejor control de la Hacienda pública, este impuesto queda recogido en partidas homogéneas aunque de forma discontinua ${ }^{38}$.

El pago del diezmo por la adquisición de un esclavo es algo tan raro de ver en la documentación que sólo hemos encontrado dos referencias al respecto y de forma generalizada. Su existencia, al menos en algunos momentos, parece que no puede ponerse en duda como se desprende de una disposición real en favor del genovés Centurión eximiéndole de pagar este impuesto por una carabela que trajo de la Mina con esclavos y otras mercancías ${ }^{39}$. Entre los privilegios de Villena gozados desde antaño y confirmados por Enrique IV y los Reyes Católicos en 1476, está, tanto si sus habitantes se dirigen a Castilla o a Aragón, el de

«non pagar diezmo nin portadgo nin almoxarifazgo... de pan e vino e figos e ganado e de todas e qualesquier mercaderías que suyas propias fuesen...

\footnotetext{
35 "Rastro queda en el arancel de servicios demésticos difundidos, prestados por esclavos de todos los colores y de ambos sexos, y concentra tantos Sevilla, que con ellos abastece otras tierras. O.c. Lib. II. Cap. VI.

36 Archivo de protocolos notariales de Cordoba. Protoc. 24. Fol. 553.

${ }^{37}$ AGS. Registro del Sello. Córdoba 16 de septiembre de 1485.

${ }^{38}$ Un ejemplo lo podemos tener en el AGS en la sección Contaduria Mayor; en el Leg. 3 se nos ofrece una relación del aimojarifazgo de los esclavos de la vílla de Carmona y otras desde 1580 a 1599.

39 AGS. Registro del Sello. Medina del Campo 3 de abril de 1486.
} 
eçebto que siempre pagaron el dicho diezmo e almoxarifazgo e portadgo e otros derechos de oro e moro e cavallos e de otras cosas vedadas..." 40

Este privilegio quedó también refrendado en la "Suscripción de Contadores Mayores", tenida en Córdoba el 20 de agosto de 1484, lo que nos confirma cómo este derecho-impuesto recayó, al menos en algunos momentos, en los compradores de esclavos.

Fuera de los gravámenes propios de las operaciones comerciales esclavistas hay otras recetas fiscales procedentes de este tráfico que repercutían directamente sobre las administraciones locales. Nos referimos a los impuestos de portazgo, peages, derechos de paso y otros aranceles que se pagaban al transitar por determinadas jurisdicciones y que, regularmente, estaban recogidos en Fueros y Ordenanzas municipales muchas de las cuales se fijaron o recogieron por escrito en el siglo xvi. En los aranceles oficiales del Consulado de Burgos de 1572 aparece el siguiente relacionado con el esclavo:

De cada esclavo que se vendiere y comprare y navegare para todas partes, medio rreal» ${ }^{41}$.

A pesar de la fecha, creemos que esta disposición es simplemente la refundición de un impuesto tradicional recogido ahora de forma más explícita. Para la villa de Calatañazor y aldeas de su jurisdicción tenemos el arancel "del moro que se fuere a vender" y por el que hay que pagar 24 maravedíes. Es un impuesto alto y cuya cantidad sólo es igualada por el paso del metal de oro, la carga de garbanzos y el "ee la puta con su rufián" "22.

Un traslado de orden fechado en Ciudad Rodrigo el 25 de octubre de 1492 preguntando si se habian exigido a los judíos expulsados más derechos de portazgo y portazguillo que los que se debian pagar, nos permite saber lo que, en concepto de ambos, se daban por esclavos, además de encontrarnos de nuevo con el diezmo. La cuarta pregunta del cuestionario nos sitúa en el contexto:

40 SOler García, J. M., “La relación de Villena de 1575". Alicante 1969.

25 CORTÉs Alonso, V., "La esclavitud en Vaiencia durante el reinado de los Reyes Católicos". Valencia 1964, pag. 88 y ss. El quinto que se habia de entregar al rey en las incursiones bélicas referentes a esclavos está recogido también en el fuero otorgado a varias localidades. El concedido a Daroca en noviembre de 1142 por Ramón Berenguer IV se expresa así en este punto:

"Milites vel pedites daroce qui habierint in fonsado vel in cabalgada non dent quintam nisi Regi, uel domino daroce et hoc de captiuis tantum et de ganado et de pannis sericis quos nondum tisera tetiqerit et sicoeperint reqem dent illum regi...". Archivo Municipal de Daroca. Doc. núm. 1.

4) Basas FERnández, M., "El Consulado de Burgos en el siglo XVI». Madrid 1963.

${ }^{42}$ "Aranceles de los derechos de portazgo que se ha llevado y ilevan en el villa de Calatañazor e sus aldeas y jurisdición". Archivo de la Real Chancillería de Valladolid, Leg. 1233-3. 
"Yten sy saben... que los derechos que se piden e an acostunbrado lleuar por razon del... portasgo e postasguillo e diezma e alcaldia de sacas son los siguientes, los quales... se han lleuado e acostunbrado a lleuar físcalidad de esclavos en la EJaja Edad Media de diez e veynte e treynta e quarenta e, cinquenta años El más tiempo a esta parte... que memoria de omes no es en contrario...

- de todo esclauo cativo que entrare o saliere de Castilla a Portogal a de pagar noventa e tres mrs... XCIII.

- a se de lleuar por este respeto ansy para Portogal como para Castilla” ${ }^{43}$.

Cuando Diego Hurtado compra 6 esclavos en Sevilla para llevarlos al reino de Murcia, al pasar por la villa de Calasparra pretende pasar adelante sin pagar los derechos de portazgo, razón por la cual se le retienen los esclavos aduciendo que

"antes siempre los vezinos de esta çibdad an pagado los dichos de rechos de portadgos e otros derechos que los no francos acostunbran a pagar de tanto tienpo aca que memoria de omes no es en contrario.....

No obstante, se le devuelven 4 esclavos con la promesa de que pague los impuestos, pero Diego Hurtado,

«alquilo un ome desta villa que se llama Gómez Pardo sacristan e dixo que lo leuase por los montes ascondidamente la via de Mula e asi fue fecho, e aun leuaua una cautela el dicho Furtado que dio un enrique al dicho Gomez Pardo que si salian a el guardas el dicho G6mez Pardo fuese a todo correr a las guardas que saliese a ellos que les dixiese como les yua a pagar el derecho de la dicha Calasparra el dicho Furgado e se fue a Mula con los dichos esclauos" ${ }^{44}$.

Descubierta esta nueva anomalía se le sustraen definitivamente los 2 esclavos por "ser digno e meresçedor de auerlos perdidos". En estos casos o bien se vendían los esclavos ingresando el montante en la Hacienda real o se entregaban directamente al fisco. En este hecho particular se siguió el primer camino:

"si estos dichos dos esclauos que yo me detoue fueran en mi poder que no los auiera vendido... yo vos los ouiera dado e enbiado gracioçamente..."

Así se expresa el comendador del Concejo de Moratalla al Concejo de Murcia que pedia explicaciones por lo ocurrido a Diego Hurtado, vecino de esta ciudad.

43 Archivo ducal de Frias. Caja 16. Carpeta 12. Carrete Parrondo, C. "Fontes ludaerorum Regni Castellae". I. Provincia de Salamanca. Salamanca 1981.

A4 Archivo Municipal de Murcia. Caja 22, n. ${ }^{\circ} 33$. Moratalla 19 de octubre de 1495. 
En los Capbreu de Peages de varios lugares y villas del reino de Aragón, se hace expresa mención de lo que los esclavos han de pagar al pasar por dichos territorios:

Jaca: "Item, moro cativo, siet sueldos..."

Fraga: "Item, todo esclavo o esclava que passara por la dita villa o por sus terminos, paga cada uno un sueldo".

Calatayud: "Moro o mora que se pague de page el vinteno."

Monzón: “ltem, de cativo sarracyn un sueldo."

Este mismo peage se paga en Vinacel, Vallonga, Alfantega, Coffita, Ariestolas, Castillón del Puent de Monçon y Barca de Pomar.

Aynsa: "Item, cautivo o cautiva, cada uno pague un sueldo".

Mequinenza: "De tot esclau o esclava a cavall, dos sueldos. De si passa a peu, un sou» ${ }^{45}$.

El celo en el cobro de estos derechos solía ser ejemplar, requisando los portazgueros los esclavos que no pagaran sus derechos o reteniendo tantos de ellos cuantos fueran necesarios para reunir el valor que se debiera pagar por toda la mercancía. La contundencia observada en el caso murciano no es un hecho aislado y en ocasiones vemos actuar al propio rey para poner las cosas en sus justos límites y corregir los excesos de los perceptores quienes, a veces, no se atenían a razones. En uno de estos momentos vemos al propio rey, a petición de unos mercaderes toledanos, obligar al portazguero de Talavera de la Reina a devolverles ciertas mercancías y una esclava que les tomó porque los vecinos de Toledo tienen el privilegio de exención de portazgo ${ }^{46}$.

En el reino de Valencia la administración central explotaba en beneficio propio parte de estos derechos, pues los esclavos moros que se rescataban y querían volver a su patria de origen o ir a vivir a comunidades musulmanas lejanas al lugar en donde habían conseguido su liberación, tenian que satisfacer diversas cantidades para obtener tal permiso que, en el primer caso, aparecen en las Cuentas del Mestre Racional bajo el nombre de «Rúbrica de delmaments de sarrahims". Se pagan varios impuestos por los siguientes conceptos: diezmo del vestido que son 2 sueldos, el derecho de media dobla o 9 sueldos, el besante o 4 sueldos y el diezmo del rescate. Cuando el

\footnotetext{
${ }_{45}$ Los aquí mencionados están contenidos en "el Registro del año Mccccxxxvı de las Cortes celebradas por la Reyna doña Maria Lugarteniente general del Rey don Alonso, convocadas en la villa de Monçon y fenescidas en la villa de Alcañiz". Apartado "Sentencias \& capbreus de los Peages». Savall, P., «Fueros, Observancias y Actas de Corte del Reino de Aragón». (Observantiarum Regni Aragonum). Zaragoza 1866.

46 AGS. Registro del Sello. Fol. 384. Madrid 22 de noviembre de 1494
} 
rescatado decide vivir dentro de alguna de las morerías del país debe obtener entonces el "Permiso de cambio de residencia" que también llevaba anejo el pago de unos cuantos impuestos. Son los mismos que los considerados en el caso anterior más otra cantidad variable según la región donde se dirigieran. Ordinariamente la permanencia en estos lugares era temporal mientras satisfacian las deudas contraídas por su liberación y pagaban los préstamos recibidos a tal efecto. Pasado este tiempo, la mayoria de los cautivos valencianos regresaba a Granada o a puntos del norte de África. Finalmente, para los libertos no valencianos que debian pasar por tal reino para llegar a su lugar de destino tenían que satisfacer el «Derecho de paso" cuyo coste era de 1 besante ${ }^{47}$.

Otra receta fiscal obtenida de los esclavos era la «Licencia para men digar" con objeto de allegar fondos para su liberación. Eran concedidas directamente por el rey y, mientras que las cartas consultadas en Castilla no hacen referencia al pago de ningún derecho, las "Licencies de acapte» concedidas por el Bayle General valenciano costaban 10 sueldos. La duración de éstas en Castilla solía ser el «tiempo de una provisión" y los lugares también quedaban determinados en la carta. A pesar de este control muchos esclavos, tal vez por sustraerse al pago de las mismas, salian a mendigar sin este permiso en cuyo caso, si eran descubiertos, se los vendía en pública subasta entregando un tercio del coste a la persona que los había descubierto ${ }^{48}$. Relacionado, incluso, con la redención de cautivos parece ser que existía un impuesto especial sobre ciertas fiestas musulmanas exigible en zambras y esposorios. Era el "tarcón". Un texto pidiendo que no se cobre a partir de 1517 es lo que nos induce a pensar en la existencia de tal derecho:

«... y lo otro, porque si haber las dichas zambras es cosa licita e provechosa porque se allega en ellas para rescate de cautivos e para otras buenas obras, no parece ser cosa justa que de esto haya quien tenga derechos, sino todo sea para el buen fin para que se hace..." ${ }^{49}$.

Para completar el panorama fiscal esclavista hay que mencionar también el dinero proporcionado por las sanciones al cometer los esclavos actos delictivos 0 , simplemente, prohibidos. Bien es verdad que en la ma-

47 Estos aspectos sobre la fiscalidad esclavista valenciana pueden encontrarse más amplia mente expuestos en: PILES Ros, L., "Apuntes para la historia económica-social de Valencia durante el sigio XV». Valencia 1969 , págs. 161-171.

${ }_{48}$ Interesante y sugestivo a este respecto es el trabajo de: LóPEz ELUM, P., "Apresamiento y venta de moros cautivos en 1441 por "acaptar" sin licencia". Al Andalus 1969.

49 Archivo del Ayuntamiento de Granada. "Libro de Cabildos de 1516 a 1571 " Fol. 101. Requermiento del 21 de enero de 1517. 
yoría de los casos son los dueños los que han de satisfacer las cantidades consignadas, pero, en último término, la causa instrumental de las mismas son los propios esclavos y ellos son los responsables de que el fisco consiga otros ingresos atípicos. En las ordenanzas de la villa de Baena se prohíbe a los gacis que acojan a cualquier esclavo bajo pena, la primera vez, de $600 \mathrm{mrs}$. En las de Murcia tal delito se paga con $300 \mathrm{mrs}$. y otros menores, como andar por la noche, beber en dias festivos o juntarse en grupos estos mismos días por la tarde, se castigaba cada uno de ellos con $30 \mathrm{mrs}$. en concepto de carcelaje ${ }^{50}$. Por una pragmática del 22 de julio de 1492 a los esclavos blasfemos reincidentes en este delito se los castigaba con destierro y multa de $1.000 \mathrm{mrs} .{ }^{51}$ Para el barco portugués que recalara en Canarias y sacara sin licencia alguna ciertas mercancias, entre las que se contaba el esclavo,

"Que pierda el navío y la tercia para el acusador y la otra tercia para la camara e fisco e la otra parte para los propios" ${ }^{52}$.

Asimismo se mandó a los taberneros tinerfeños que no den de comer a esclavos sin duerño bajo pena de $600 \mathrm{mrs}$. y que éstos, donde fueren o estuvieren, lleven licencias de sus amos, de forma que si algunos descubren que tal esclavo anda sin dicha licencia y no le lleven a la cárcel,

"pague cinco mill mrs. de pena para los propios desta ysla» ${ }^{53}$.

A veces, la determinación particular en el momento de imponer sanciones superaba toda proporcionalidad con respecto al delito cometido recurriéndose al rey para poner remedio a esta situación. En un pelito entre las villas de Niebla y Moguer Pedro Portocarrero, señor de esta última, se quejaba a sus majestades:

«... que si algunos vesinos de la villa de Moguer fallan en sus terminos (de Niebla) faziendo lena... les llevan derechos muy deshordenados llevando un asno e un esclavo por una carga de lena que sacan de sus terminos... " ${ }^{54}$.

En esta misma línea podemos también considerar todo lo que el fisco real ingresaba cuando castigaba con reducción a esclavitud y confiscación de bienes a todas aquellas personas que transgredian algunas nor-

\footnotetext{
50 Valverde y Perales, P., "Historia de la villa de Baena". Toledo 1903. Ordenanza del 28 de marzo de 1538. Archivo Municipal de Murcia. Actas Capituales 1502-1503. Fols. 231-232.

"Libro de las Bulas y Pragmáticas de los Reyes Católicos". 22 de julio de 1492. Fols. 2-3.

2 Serra Rafols, E.; Rosa, L., "Acuerdos del Cabildo de Tenerife" en Fontes Rerum Canariarum, T. IV y V. Acuerdo tomado el 17 de mayo de 1506.

53 Ibidem, Acuerdo del 8 de enero de 1507 y 23 de abril de 1507.

\$4 AGS. Registro del Sello. Fol. 125. 1480.
} 
mas que conllevaban esta pena. Por ejemplo, cuando se conmina a los mudéjares de Ronda, Marbella y Casarabonela a que no abandonen sus lugares de residencia, se les advierte clamanente:

«so pena que qualquier que fuere a bevir a qualquier logar o logares fuera sea finque esclavo de qualquier que to fallare yendose a bevir o saliendo fuera de su logar donde fuere avezindado quando le tomamos por nuestro lo pueda tomar e tome e todos sus bienes muebles e rayzes sean para la nuestra camara e fisco» ${ }^{55}$.

Medidas como ésta aburıdan frecuentemente para tratar de controlar a la población musulmana.

Otra corriente económica provocada por los esclavos indirectamente relacionada con su vertiente fiscal eran las compensacionies pecuniarias que se ofrecían por su captura en caso de huida. La costumbre había ido estableciendo cantidades diferentes según los lugares: en Canarias se ofrecía una doble de oro, en Valencia entre 2 y 5 libras, etc. Esto no impedía que el mismo dueño, por su cuenta, ofreciera otras cantidades a quien mejor juzgare oportuno. Este asunto, con el tiempo, llegó a ser considerado en las Cortes de 1551, proponiendo los procuradores en su petición CIIl que el horro

«que tomare esclavo fugitivo lleve de precio en prenderle mil maravedís, $y$ ansi escusaran los esclavos de ser fugitivos..." ${ }^{56}$.

No fue aceptada esta propuesta por el monarca tal vez porque el dinero que se debería dar a estos libertos tendría que salir de su propia hacienda. En la baja Edad Media para hacer frente al aluvión de fugas se ideó una "caja de seguros" en Cataluña para cubrir este riesgo. Cada dueño declaraba en dicha caja los esclavos que tenía pagando una cantidad por cada uno de ellos; en caso de huida la entidad indemnizaba según lo estipulado. La importancia de esta institución debió ser grande a juzgar por las veces que intervino. Por citar un ejemplo diremos que desde 1421 a 1430 gestionó indemnizaciones por 324 casos de fugas.

Finalmente hay que hacer alusión a casos en que ciertos documentos eximen del pago de algún derecho por los esclavos y todo parece apuntar que se trata de esclavos cristianos. Así, por una petición real se manda que no se exijan a Juan Ramírez, vecino de Sevilla, derechos por un esclavo cristiano que le sirve. En el mismo sentido contamos con otra carta

55 Ibidem. Zaragoza 10 de enero de 1488. Fol. 281.

56 "Cortes de los antiguos reinos de León y de Castilla", publicadas por la Real Academía de la Historia. Cortes celebradas en Madrid en 1551. T.V. 
para un tal Yuce, judío vecino de Córdoba, en que se le manda que devuelva a Alfonso de Castro un esclavo que le tomó; la causa de esta devolución no es otra que el haberse negado a pagar los impuestos pertinentes, alegando el judío que ese esclavo era cristiano ${ }^{57}$. Fuera de estas dos citas extrañas no hemos encontrado ninguna legislación adecuada que ampare de esta forma a los propietarios de esclavos cristianos, antes al contrario, en muchos casos de compra-venta se hace alusión al esclavo de quien se dice que está bautizado o es cristiano y su dueño debe cumplir con todos los requisitos fiscales que dicha transacción llevaba consigo.

57 AGS. Registro del Sello. Fol. 263, Sevilla 28 de enero de 1490 y 29 de enero de 1491. Fol. 181 